\title{
Palliative side-to-side oesophagogastrostomy for unresectable carcinoma of the oesophagus and cardia
}

\author{
KOING-BO KWUN AND PAUL A KIRSCHNER \\ From the Department of Surgery and Division of CardioThoracic Surgery, Mount Sinai School of Medicine \\ of the City University of New York, New York, USA
}

\begin{abstract}
The distressingly low resectability rate of carcinoma of the oesophagus and gastric cardia emphasises the need for palliative restoration of the act of swallowing. Side-to-side oesophagogastrostomy was performed in 10 cases of unresectable tumours. Eight anastomoses were made low in the left chest for lower third oesophageal and cardiac lesions and two high on the right for midoesophageal tumours. There were no anastomotic leaks or other complications, and no postoperative deaths. All patients swallowed well for an average of five months until their deaths. The decision to use this procedure is made at the time of thoracotomy when resection of the cancer is impossible because of local invasion and when sufficient proximal oesophagus is available for the anastomosis. The operation involves a single suture line only. It provides immediate palliation of dysphagia and makes unnecessary additional technical manoeuvres such as preparation of colonic or jejunal loops insertion of endoluminal tubes, or even transection of the oesophagus, pyloroplasty, gastrostomy or cervical oesophagostomy. It does not interfere with any subsequent radiotherapy or chemotherapy
\end{abstract}

Resectability of carcinoma of the oesophagus and gastric cardia is distressingly low despite occasional recent reports to the contrary. ${ }^{12}$ Cure rates are dismally lower. Local invasion and fixation of the tumour are the main factors precluding resection. The prime object of palliation is restoration of swallowing, which should be achieved as simply and as quickly as possible. In 10 patients with unresectable tumours we have employed side-to-side oesophagogastrostomy between the gastric fundus and the oesophagus above the tumour.

\section{Historical background}

In 1911 Heyrovsky $^{3}$ reported the first oesophagogastrostomy between the distal oesophagus and fundus of the stomach for idiopathic dilatation of the oesophagus. The earliest palliative oesophagogastric bypass for cancer was performed by Tanner ${ }^{4}$ in England in 1946 for a mid-oesophageal tumour. He stated: "The growth was inoperable but it was a simple matter by traction on the oesophagus to pull the stomach into the right chest and make a short circuit between the fundus and the higher oesophagus." Despite the simplicity and success of this

Address for reprint requests: Dr PA Kirschner, 2 East 92nd Street, New York, NY 10028, USA. manoeuvre, most British surgeons favoured an oesophago-jejunal bypass using a Roux-en-Y loop of jejunum as described by Allison ${ }^{5}$ in the same year. Shortly after this, d'Allaines and associates ${ }^{6}$ in France described palliative oesophagogastrostomy in eight cases of carcinoma and one caustic stricture. Seven of the tumours were in the lower third or cardia and were approached through the left chest; one was a mid-oesophageal lesion treated using the separate abdominal and right thoracic incisions described by Tanner. In one case, the oesophagus was ligated between the tumour and the anastomosis. There were two deaths, one from shock, the other from an anastomotic leak.

At the same time, Olivier et $a l^{7}$ applied this technique to mid-oesophageal lesions and collected seven cases from French publications with four successes and three deaths.

Lortat-Jacob $^{8}$ advocated transection of the oesophagus to exclude the carcinoma in order to prevent regurgitation which occurred in his five cases. He had no operative mortality.

Miller ${ }^{9}$ performed palliative bypass in 22 cases with a $55 \%$ mortality. Average survival was three and a half months, the longest being seven months. Four patients were not relieved of dysphagia and three had severe acid or biliary reflux.

Bickford ${ }^{10}$ reported an additional 10 cases from 
the same clinic with a $33 \%$ mortality and an overall survival of under five months.

Le Roux ${ }^{11}$ bypassed 16 cases, using the stomach in four, the jejunum in 11 , and the colon in one. There was a $50 \%$ mortality, but it could not be determined from the article in which type of bypass there were fatalities.

In our institution, Garlock ${ }^{12}$ recommended this type of oesophagogastric bypass. No previous reference to this procedure could be found in American reports.

In 1970, Johnson and Clagett ${ }^{13}$ of the Mayo Clinic described the technique of oesophagogastric bypass for carcinoma of the cardia. They advocated transection of the oesophagus between the anastomosis and the tumour. Interestingly enough, in the same year there was another report from the Mayo Clinic by Gunnlaugsson et al ${ }^{14}$ of 1657 cases including 505 resections and only two bypasses without resection, the colon being used in both.

\section{Technique}

The route of surgical access is determined by the level of the tumour. Cardiac tumours are exposed via a left abdominothoracic incision (occasionally a left thoracotomy alone suffices) while midoesophageal neoplasms require separate laparotomy and right thoracotomy. Upper third and cervical oesophageal lesions cannot be treated in this way as there is no free oesophagus proximal to the tumour available for anastomosis.

The abdomen is opened first. We prefer the KraftFry incision ${ }^{15}$ because of the excellent exposure. For lower lesions, it is converted into an abdominothoracic incision. For the higher tumours, the abdominal incision is closed after gastric mobilisation, and a separate right thoracotomy is made.

The extent of mobilisation of the stomach depends on the location of the tumour. Cardiac lesions rarely extend to involve the fundus or greater curvature so that this part of the stomach is freely and easily rotated into the left lower chest after appropriate ligation of the vasa brevia and left gastroepiploic arteries (fig 1). The left gastric artery need not be divided. However, oesophagogastric anastomosis at or above the aortic arch (or azygos vein) for mid-oesophageal tumours requires complete gastric mobilisation, preserving only the right gastric and right gastroepiploic vessels and the epiploic arch. The left gastric artery must be divided as well, and Kocher's manoeuvre to mobilise the proximal duodenum, and release of the distal oesophagus are also required for the high anastomosis (fig 2).

At either level, the stomach can be rotated easily and raised to a suitable point above the non-mobilised fixed unresectable carcinoma. A side-to-side oesophagogastrostomy is effected using sutures or the GIA stapling apparatus (Auto Suture Model GIA, United States Surgical Corporation). We prefer a longitudinal incision in the oesophagus in contrast is to d'Allaines' preference for a transverse incision. $\vec{\circ}$ This allows for a much larger anastomosis not limited by the oesophageal diameter, and less $\vec{\omega}$ mobilisation of the proximal oesophagus is necessary. The oesophagus has not been ligated or divided $x$ in any case. This preserved its intramural vascular integrity and contributed to the primary healing $\sigma$ of the anastomosis in all our 10 cases. No patient experienced reflux. A naso-gastric tube may be passed

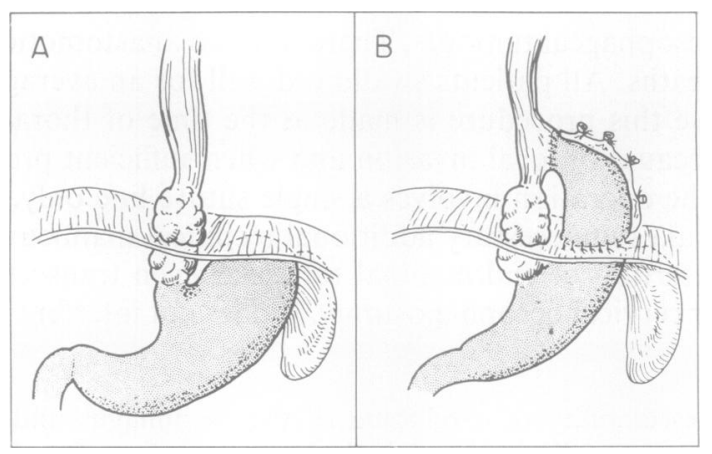

Fig 1 Low oesophagogastrostomy. (A) Tumour at oesophagogastric junction or lower oesophagus.

(B) Displacement of gastric fundus into the left chest and oesophagogastric anastomosis above tumour.

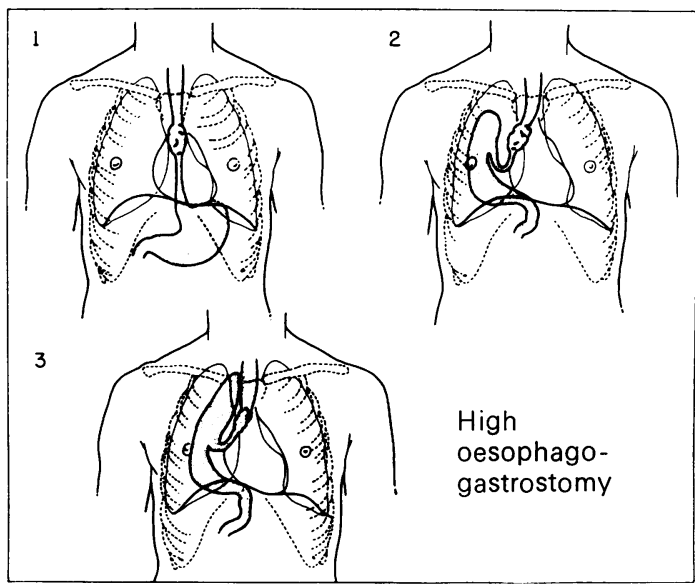

Fig 2 Tumour of mid-oesophagus (1); mobilisation and displacement of stomach into the right pleural cavity (2); Oesophagogastric anastomosis above tumour (3). 
through the anastomosis for gastric decompression. The remainder of the operation and the postoperative care are as in standard oesophagogastrectomy. Pyloroplasty is unnecessary unless organic obstruction is present. Oral intake is begun on the seventh postoperative day after a radiological study has demonstrated a patent intact anastomosis, and rapidly increased to a regular diet. Intravenous hyperalimentation may be used during the first week.

\section{Results}

The results in the 10 cases are summarised in the table. There were six adenocarcinomas (five cardiac and one lower third of oesophagus) and four squamous carcinomas, two in the middle third and two in the lower third.

Eight low left and two high right bypasses were performed. Three staple and seven suture techniques were used for the anastomosis. None leaked or developed a stricture. Only one pyloroplasty was done. There were no operative deaths or major complications. All patients left the hospital no later than two weeks after operation, eating and swallowing well. There were no difficulties with reflux or gastric emptying. Radiographs revealed a widely patent anastomosis in all cases (figs 3, 4). The preferential route of ingested material was through the anastomosis; even partially obstructing tumours closed off completely. In no case did tumour overgrow the anastomosis up to nine months later. In the patient who survived nine months a flexible oesophagoscope traversed the anastomosis easily at that time. Average survival after operation was five months. The quality of life was reasonably good marred only by progression of the incurable carcinoma rather than by postoperative sequelae or recurrent dysphagia.

\section{Discussion}

Palliative oesophagogastrostomy is indicated in the large group of patients found to be locally unresectable. In the period of time encompassed by these 10 patients (1972-78) 92 patients underwent operations for oesophageal and cardiac tumours at our institution. Thirty-nine per cent (34 patients) had unresectable growths. It is difficult to state how many of these were candidates for this palliative procedure, as it was used selectively and not routinely. It may be surmised that at least one-third or one-half of these were suitable for palliative bypass. As more surgeons become aware of the availability of this operation, they will undoubtedly use it more liberally rather than persist in futile attempts to resect fixed invasive tumours where there is no hope of cure.
The simplicity of the procedure, which involves only one anastomosis, results in a lower morbidity and mortality than in more extensive palliative procedures.

The stomach can be easily mobilised to reach well above the azygos vein to the apex of the chest-

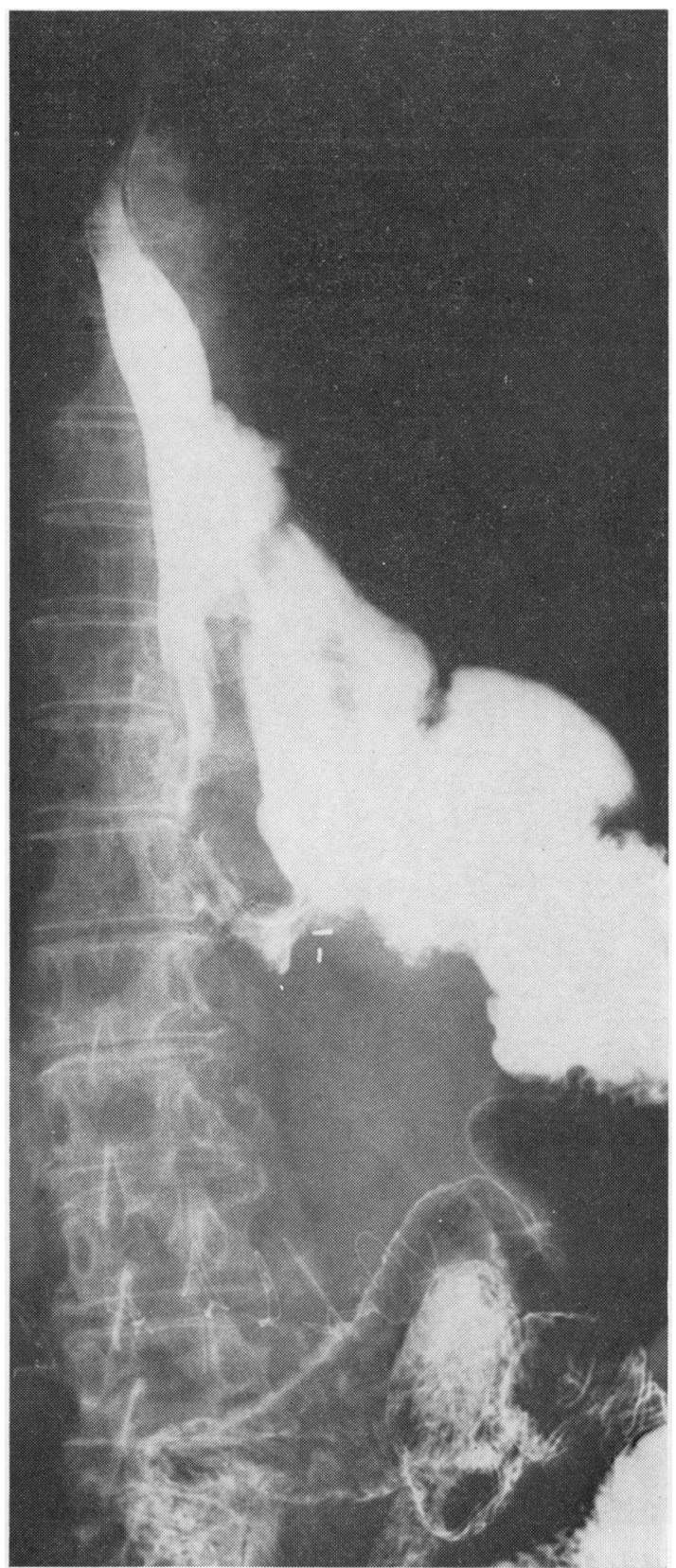

Fig 3 Barium swallow after lower oesophagogastrostomy. 
Table Results of oesophagogastrostomy.

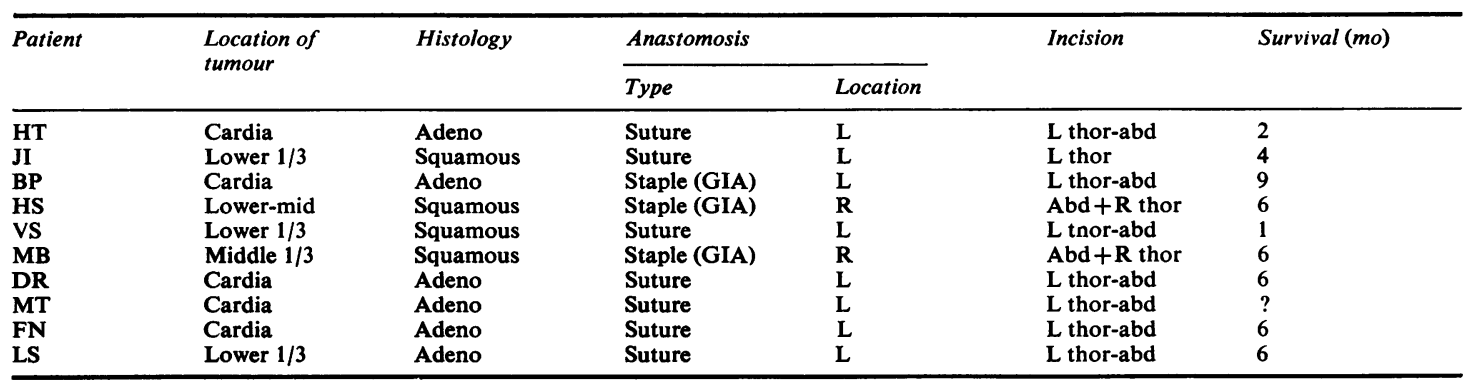

Adeno=adenocarcinoma; $\mathbf{L}$ thor-abd=left thoraco-abdominal; $\mathbf{A b d}=$ abdominal; $\mathbf{R}$ thor=right thoracotomy.

the highest point at which this anastomosis is feasible - without the necessity for division of the oesophagus In every case that this procedure was started it could be completed satisfactorily.

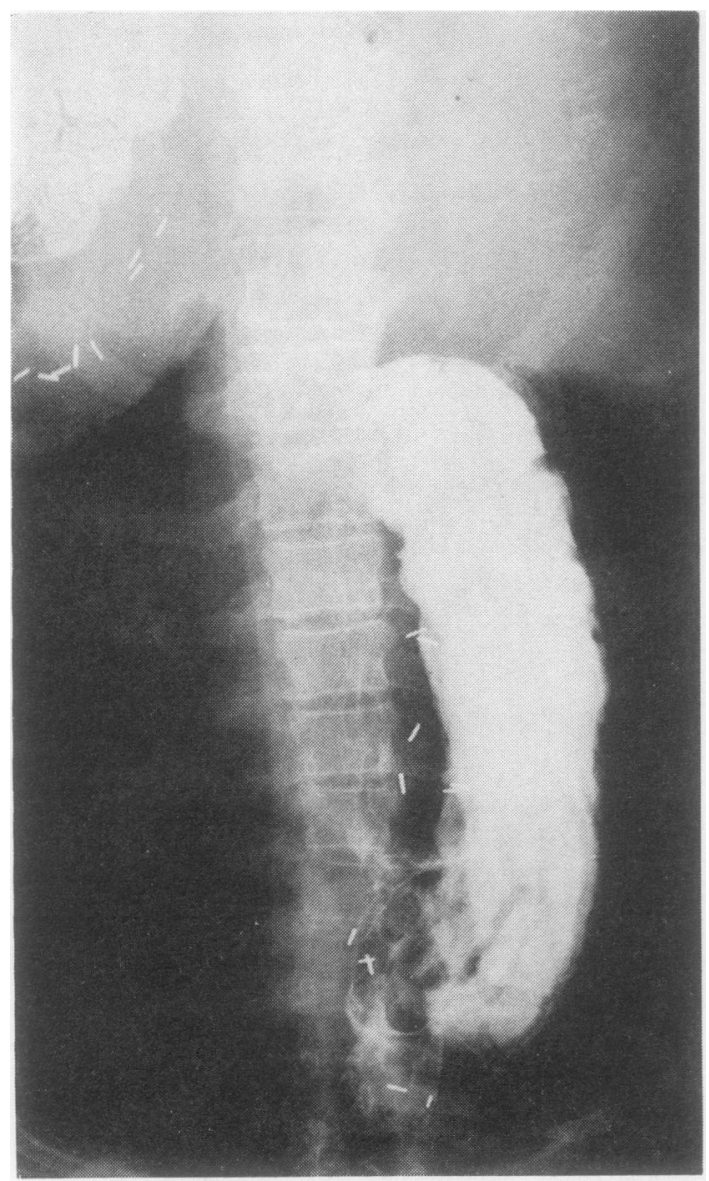

Fig 4 Barium swallow after high oesophagogastric bypass.
Excessive mobilisation of the proximal oesophagus is avoided by the use of a longitudinal anastomosis, and a large aperture is easily obtained. Overgrowth of the anastomosis by the tumour causing recurrence of dysphagia has not occurred, though it is theoretically possible.

Preferential flow of ingested food is through the anastomosis, the tumour lumen closing off promptly; and reflux problems were not experienced in any patient.

It is interesting to speculate what role oesophagogastric bypass without resection has for benign high obstructions. We know that the Heyrovsky procedure and its modifications for achalasia often led to severe reflux oesophagitis. However, this may not be the case in high strictures, and if so, surgical amelioration may be simplified.

\section{Addendum}

This paper was originally presented before the New York Surgical Society on 19 April 1979. It was first submitted for publication on 25 September 1979. Since that time an additional paper ${ }^{16}$ has appeared.

We wish to thank Dr Arthur Aufses Jr, Dr Albert Frankel, and Dr Arthur Sicular for permission to include each of their cases.

\section{References}

1 Payne WS, Pearson JG, Ellis FH Jr, Parker EF. Carcinoma of the esophagus (Symposium). Contemp Surg 1978; $12: 50$.

2 Piccone A, LeVeen HH, Ahmed N, Grosberg S. Reappraisal of oesophagogastrectomy for oesophageal malignancy. Am J Surg 1979; 137:32.

3 Heyrovsky $\mathrm{H}$. Casuistik und therapie der idiopathischen dilatation der speiseröhre. Oesophagogastroanastomose. Arch Klin Chir 1912-13; 100:70315.

4 Tanner NC. Discussion on carcinoma of lower 
oesophagus and cardia. Section of Surgery. Proc $R$ Soc Med 1946; 39:411-22.

5 Allison PR. Oesophago-jejunostomy for irremovable carcinoma of the cardia. Thorax 1946; $1: 239-46$.

6 d'Allaines F, Dubost C, Galley JJ. Oesophagogastrostomies palliatives sans resection dans les cancers de l'oesophage et du cardia. J Chir 1949; 65:289-301.

7 Olivier C, L'anastomose palliative dans les cancers de la partie moyenne de l'oesophage thoracique. Presse Medicale 1949; 57:599-600.

8 Lortat-Jacob JL. In: Etude du traitment du cancer de l'oesophage. Reunions Chirurgicales de l'Hospital Broussais. Services de Mm. d'Allaines et Banzet. 12 December 1949.

9 Miller C. Carcinoma of thoracic oesophagus and cardia. A review of 405 cases. Br J Surg 1961-62; 49:507-22.

10 Bickford BJ. The results of palliative surgery of carcinoma of the oesophagus and cardia. Ned Tijdschr Geneesk 1962; 106:344-51.

11 LeRoux BT. An analysis of 700 cases of carcinoma of the hypopharynx, the oesophagus and the proximal stomach. Thorax 1961; 16:226-55.

12 Garlock JH. Surgery of the alimentary tract. New York: Appleton-Century-Crofts, 1967: 87.

13 Johnson CL, Clagett OT. Palliative oesophagogastrostomy for inoperable carcinoma of the oesophagogastric junction. J Thorac Cardiovasc Surg 1970; 60:269-74.

14 Gunnlaugsson GH, Wychulis AR, Roland C, Ellis FH Jr. Analysis of records of 1657 patients with carcinoma of the oesophagus and cardia of the stomach. Surg Gynecol Obstet 1940;130:997-1005.

15 Kraft RO, Fry WJ. Operative technic of selective gastric vagotomy. Am J Surg 1963; 105:423-35.

16 Popovsky J. Oesophagogastrostomy in continuity for carcinoma of the oesophagus. Arch Surg 1980; 115:637-9. 